\title{
ALVEOLAR BONE LEVEL AT DECIDUOUS \\ MOLARS IN FLEMISH CHILDREN: A \\ RETROSPECTIVE, RADIOGRAPHIC STUDY
}

Wylleman Astrid ${ }^{1}$, Van der Veken Dominique ${ }^{1}$, Teughels Wim $^{1}$, Quirynen Marc ${ }^{1}$, Laleman Isabelle ${ }^{1}$

${ }^{1}$ Section of Periodontology, Department of Oral Health Sciences, KU Leuven \& Dentistry Department, University Hospitals Leuven, Kapucijnenvoer 33, 3000 Leuven, Belgium

Running title: Marginal bone level in Flemish children

Correspondence to:

Astrid Wylleman

KU Leuven

Section of Periodontology

Kapucijnenvoer 33

3000 Leuven

BELGIUM

0032.16 .33 .24 .83

astridwylleman@gmail.com 


\section{Acknowledgements}

We hereby thank Wim Coucke for the statistical analysis.

\section{Conflict of interest and Source of funding}

None of the authors have a conflict of interest to report. This study was not funded. 


\section{Abstract}

Aim: The aim of this retrospective radiographic study in Flemish children was to examine the bone level and bone loss around deciduous molars and factors influencing this.

Materials and methods: 2896 digital intra-oral radiographs of children younger than 18 years old were screened for eligibility. The distance from the cementoenamel junction to the alveolar bone crest was measured and tooth surfaces were screened for local risk factors that are presumably related to changes in the bone level. A distance $>2 \mathrm{~mm}$ was defined as bone loss based on previous literature. All measurements were performed by two examiners.

Results: 1491 radiographs of 796 patients (mean age $6.46 \pm 2.38$ years) were included.

The distance between the cementoenamel junction and the alveolar bone crest ranged from 0.07$2.88 \mathrm{~mm}$ and the mean distance was $0.93 \pm 0.37 \mathrm{~mm}$. This distance was positively correlated with age $(p<0.001)$. In $3.5 \%$ of patients, bone loss was diagnosed. Caries, fillings and pulp pathology were associated with bone loss and higher cementoenamel junction - alveolar bone crest distances $(p<0.05)$.

Conclusion: This study found a low prevalence of alveolar bone loss in the primary dentition. Both the bone level and bone loss were strongly correlated to local factors.

Keywords: alveolar bone loss; bitewing radiography; child; adolescent 


\section{Clinical relevance}

Scientific rationale: The marginal bone level around deciduous teeth in Flemish children has never been studied before. Also, this is the first study assessing the bone level on digital radiographs.

Principal findings: The distance between the cementoenamel junction and the alveolar bone level was in line with previous literature. It was strongly correlated to local factors in the dentition. The prevalence of bone loss was low and could mostly be attributed to factors other than periodontitis.

Practical implications: Bitewing radiographs are useful in clinical practice for screening the bone level in children. However, radiographic findings should always be confirmed clinically. 


\section{INTRODUCTION}

Periodontitis in the primary dentition is a known risk factor for developing severe periodontal destruction later on in life (Albandar et al., 1991). Patients diagnosed with periodontitis in the permanent dentition at an early age ( $<20$ years old) already showed signs of bone loss on radiographs of their primary dentition. This association is stronger when the periodontal destruction of the permanent dentition is more severe and when more sites are affected (Sjodin et al., 1993). Even though periodontitis in the primary dentition is a rare disease, screening is important to detect patients at risk for further periodontal deterioration (Jenkins and Papapanou, 2001).

Periodontal screening should thus not only be an important part of the routine dental examination of adults (Garcia et al., 2016), but also of children and adolescents (Califano, 2003). In adults, the recommended screening method is based on probing (Ainamo et al., 1982). However, application of this procedure may be difficult in the primary and mixed dentition because of tooth eruption and sensitivity. In children, the most commonly used screening method is therefore the measurement of the distance between the cementoenamel junction (CEJ) and the alveolar bone crest $(A B C)$ on bitewing radiographs (Sjödin and Matsson, 1992). This method can be applied in almost all patients, since these radiographs are taken as part of a routine dental examination for caries detection.

Multiple studies tried to assess the 'normal' CEJ-ABC distance of primary teeth with divergent results, ranging from 0 to $6 \mathrm{~mm}$ (Sweeney et al., 1987, Bimstein and Soskolne, 1988, Bimstein et al., 1988, Sjödin and Matsson, 1992, Sjödin and Matsson, 1994, Needleman et al., 1997, Darby et al., 2005). Based on their findings, these authors proposed to speak of bone loss when the CEJ-ABC distance is $>2$ mm (Sjödin and Matsson, 1992, Bimstein et al., 1994). However, this is not always the result of periodontal problems. Previous studies have demonstrated that local factors such as caries, fillings, calculus and stainless steel crowns can also influence the marginal bone level (Bimstein et al., 1988, Jenkins and Papapanou, 2001). Moreover, proximal tooth surfaces adjacent to exfoliating or erupting teeth have larger CEJ-ABC distances due to alterations in bone mineral density (Sjödin and Matsson, 1992). Likewise, it has been suggested that an increased distance is assessed when primary teeth are close to being exfoliated (Bimstein et al., 1988).

Since this type of investigation has never been performed on digital radiographs, the aim of this study was to examine the bone level around deciduous molars on digital radiographs and its influencing factors. This was carried out on radiographs of Flemish children, a population that has never been investigated up to now. 


\section{Materials and methods}

This retrospective study was approved by the ethical committee of the Catholic University of Leuven with registration number mp08413.

All digital radiographs taken in children younger than 18 years old at the department of conservative dentistry of the University hospitals of Leuven (Leuven, Belgium) between June 2015 and June 2016 were analysed. Of the 2896 radiographs screened, 620 were excluded from the analysis because neither first nor second deciduous molars were projected.

All radiographs were taken with phosphor plates and digitalized with Digora ${ }^{\circledR}$ Optime devices (Soredex ${ }^{\circledast}$; Tuusula, Finland).

The primary outcome of the current study was to evaluate the marginal bone level in the primary dentition. Therefore, the distance between the CEJ and the $A B C$ was measured on the distal surface of the first deciduous molar and the mesial surface of the second deciduous molar, in both upper and lower jaw (figure 1). Distances were measured with ImageJ software (Rasband, 1997) version 1.50i after zooming in to obtain a twofold magnification. All measurements were performed by two independent examiners (DV and AW) after a calibration session on 20 radiographs. Inter-examiner variability was calculated. Each examiner measured 40 radiographs twice to determine intraexaminer variability.

Radiographs were not used for measurement when there was no perpendicular projection or because of insufficient quality. Individual sites were excluded if the CEJ or $A B C$ was not visible or could not be identified and in case of extensive overlap. Exfoliating primary molars, defined as showing extensive root resorption, were excluded for measurement. When a site was excluded by one examiner but included by the other, it was excluded from analysis.

The secondary outcome of the study was to estimate the prevalence of alveolar bone loss at primary molars, defined as a CEJ-ABC distance of $>2 \mathrm{~mm}$. To correct for measurement errors, all sites where one examiner measured a distance larger than $1.9 \mathrm{~mm}$ whereas the other had a result that differed at least $0.5 \mathrm{~mm}$, were re-evaluated by both examiners together.

Thirdly, the correlation between the presence of local risk factors in the dentition and the CEJ-ABC distance and the prevalence of bone loss was investigated. Measurement sites and adjacent proximal surfaces were screened for the presence of calculus, caries, fillings, pulp pathology or stainless steel crowns. Furthermore, the presence of an exfoliating or erupting neighbouring tooth was determined. This was carried out by the same two examiners. In case of discrepancy, the radiograph was 
discussed together to find a consensus. A site was defined as being 'healthy' when no risk factor was diagnosed on the surface itself or the adjacent surface.

The mean value of both measurements was used for analysis. Data were grouped per patient. Differences between groups were compared using a multilevel model with distance as dependent variable, group as fixed factor and observer and patient as crossed random factors. When more than two groups were involved, a correction for simultaneous hypothesis testing according to Tukey was performed when comparing groups. For the relation with age, the regression coefficient of age versus distance was considered. When groups were compared with each other for the frequency that distances exceeded threshold values of 2 and $3 \mathrm{~mm}$, a generalized multilevel model was fit for binary responses using a logit link. The same combination of fixed and random factors was used as for the distance. 


\section{Results}

In total, 2276 digital radiographs were screened of which 785 were excluded. This resulted in 1491 radiographs of 796 patients, 418 boys (52.51\%) and 378 girls (47.49\%). Patients were between 1 and 15 years old, with a mean age of $6.46 \pm 2.38$ years. On these radiographs, 4585 measurements, 2145 in the upper jaw and 2440 in the lower jaw, were performed. The demographics of the included patients and the distribution of measurements are shown in table 1.

The intra-examiner and inter-examiner agreement was 0.59 for both examiners, and 0.61 respectively.

\section{Marginal bone level}

The range of the CEJ-ABC measurements was 0.07 to $2.88 \mathrm{~mm}$ and the mean CEJ-ABC distance was $0.93 \pm 0.37 \mathrm{~mm}$. This distance was positively correlated with age $(p<0.001)$ (fig. 2$)$. There was a tendency towards a higher mean distance in male subjects than female subjects $(p=0.05)$. For the upper and lower jaw, the mean distance was $0.98 \pm 0.37 \mathrm{~mm}$ and $0.89 \pm 0.38 \mathrm{~mm}$ respectively. This difference was statistically significant $(p<0.001)$. Moreover, measurements on the distal surface of the first deciduous molar in the upper jaw were significantly higher than on other tooth surfaces $(p<0.05)$. (table 2)

To determine the correlation between the risk factors and the CEJ-ABC distance, three comparisons were performed. Firstly, in $58.78 \%$ of the measured sites (2695 tooth surfaces), either the surface itself or the adjacent surface was diagnosed with caries, calculus, fillings and/ or stainless steel crowns or there was an exfoliating/erupting adjacent tooth. These were compared to healthy surfaces. The mean CEJ-ABC distance in the first group was $0.96 \pm 0.4 \mathrm{~mm}$ and was significantly higher than the mean distance in the second group, namely $0.90 \pm 0.34 \mathrm{~mm}(p<0.001)$ (fig. 3). Secondly, tooth surfaces with only a risk factor on the surface itself were compared to healthy surfaces. The mean CEJ-ABC distance was significantly higher in the first group as well (respectively $0.99 \pm 0.37 \mathrm{~mm}$ and $0.90 \pm 0.34 \mathrm{~mm})(p<0.001)$. Lastly, the comparison between the mean CEJ-ABC distance on intact surfaces with a risk factor on the adjacent surface and the mean CEJ-ABC distance on healthy surfaces was not significantly different. (table 2 )

When evaluating all factors separately, only caries, fillings and pulp pathologies were significantly associated with a higher CEJ-ABC distance $(p<0.05)$. The presence of a steel crown on the investigated or adjacent tooth and the presence of an exfoliating or erupting adjacent tooth was not significantly associated with this distance $(p=0.12$ and $p=0.14)$. Calculus was diagnosed radiographically only twice in the primary dentition, which made the calculation of a correlation 
impossible. The correlation between the mean CEJ-ABC distance and certain risk factors is shown in table 2 .

\section{Marginal bone loss}

In this sample, 32 measurements $(0.70 \%)$ were larger than $2 \mathrm{~mm}$. These belonged to 28 patients (3.52\%) (table 3). Only one measurement (0.02\%) was higher than $3 \mathrm{~mm}$. However, of the 32 tooth surfaces with a CEJ-ABC distance $>2 \mathrm{~mm}, 26$ were diagnosed with a risk factor on this surface or the adjacent surface, compared to 6 healthy surfaces. The sole measurement larger than $3 \mathrm{~mm}$ was diagnosed on a surface with extensive decay.

There was a tendency that male subjects had more bone loss than female patients, $1.1 \%$ and $0.2 \%$ respectively $(p=0.054)$.

The mesial surface of the second deciduous molar in the lower jaw was most frequently affected by bone loss, but not significantly more in comparison to other sites. The difference with the distal surface of the first deciduous molar was small, $0.83 \%$ of measurements compared to $0.81 \%$. Even though the mean CEJ-ABC distance was significantly higher in the maxilla compared to the mandible, bone loss was diagnosed more frequently in the latter. In the lower jaw, $0.82 \%$ of the surfaces showed bone loss, contrary to only $0.47 \%$ in the upper jaw $(p<0.001)$. If jaw type was left out of consideration, first deciduous molars were affected slightly more $(0.75 \%)$ than second deciduous molars $(0.57 \%)$. However, this difference was not statistically significant. (table 4$)$

There was a strong association between the diagnosis of a risk factor on the tooth surface itself and/ or the adjacent surface and the presence of a CEJ-ABC distance $>2 \mathrm{~mm}(p<0.001)$. Caries, filling and pulp pathology showed the same association, but only when diagnosed on the surface where the measurement was performed. The presence of an exfoliating primary tooth or erupting tooth was not related to bone loss. Bone loss was not diagnosed or rather rare on teeth with calculus and steel crowns, therefore no association could be determined. (table 4) 


\section{DISCUSSION}

This is the first study describing the mean CEJ-ABC distance on digital radiographs and the factors influencing this. The study population consists of 796 Flemish children. A mean CEJ-ABC distance of $0.93 \pm 0.37 \mathrm{~mm}$ was measured. This distance was correlated with increasing age. Moreover, it was significantly higher in the upper jaw, on the distal surface of the first deciduous molar in the upper jaw and when caries, fillings and pulp pathologies were present. Values larger than 2 or $3 \mathrm{~mm}$ were scarce, respectively $0.70 \%$ and $0.02 \%$ of all measurements and $3.52 \%$ and $0.13 \%$ of all patients. The lower jaw was significantly more affected by bone loss than the upper jaw. Despite the low prevalence rate, bone loss was significantly associated with the presence of caries, fillings and pulp pathology.

Bitewing radiographs are often seen as the gold standard for periodontal screening in the primary dentition. However, this can only be used correctly when the normal bone level in young children is known. In previous studies, different authors have assessed the mean CEJ-ABC distance in different study populations, reporting values which are in line with our result of $0.93 \pm 0.37 \mathrm{~mm}$ (Bimstein and Soskolne, 1988, Sjödin and Matsson, 1992, Darby et al., 2005). As for the correlation of this distance with age and gender, the current study only found a significant association for the former, which is an observation that was already assessed on analogue radiographs by Bimstein and Soskolne in 1988 (Bimstein and Soskolne, 1988) and was confirmed in other studies as well (Bimstein and GarciaGodoy, 1994, Bimstein, 1995, Shapira et al., 1995). This physiologic process might be related to continuous tooth eruption as a result of facial growth and attrition (Bimstein et al., 1993a).

Contrary to the mean distance, the range in CEJ-ABC distances seems to vary widely in different studies, which is attributed to different factors that may influence this distance. Some are inherent to the studied population such as age, jaw type, tooth type... Others relate to the prevalence of certain local factors in the dentition, for example caries, fillings and pulp pathologies, for which the current study found a significant association (Darby et al., 2005, Sjödin and Matsson, 1992).

Two authors demonstrated a strong correlation between the CEJ-ABC distance and the presence of exfoliating or erupting adjacent teeth (Bimstein et al., 1988, Sjödin and Matsson, 1992). Surprisingly, the current study could not find such an association. However, it has been stated that during the intraosseus phase of tooth eruption, bone resorption and bone formation occur simultaneously to form a pathway for the tooth to the occlusal plane. For permanent teeth, this phase is preceded by root resorption of the primary tooth. Both processes would induce a modification of the bone mineral density on radiographs. This would explain the increased distances to the alveolar bone 
(Marks and Schroeder, 1996). However, since the current study used digital radiographs, it is possible that the bone that is still present but less dense, is better visualized than on analogue radiographs.

The results found in the current study and former similar studies support a $2 \mathrm{~mm}$ cutoff point for alveolar bone loss in the primary dentition. Moreover, the literature indicates that the highest prevalence of bone loss appears between the two primary molars (Bimstein et al., 1988, Bimstein, 2018). With this knowledge, many authors have tried to assess the prevalence rate by measuring the CEJ-ABC distance between the primary molars on radiographs of young children. However, results vary enormously and the current literature still has not reached a consensus. Studies published between 1987 and 2018 have reported prevalence rates for marginal bone loss varying between 0.84\% and 39\% (Sweeney et al., 1987, Bimstein et al., 1988, Bimstein et al., 1994, Sjödin and Matsson, 1994, Carranza et al., 1998, Bimstein et al., 1996, Darby et al., 2005, Bimstein, 2018). The prevalence rate in the current study was rather low, namely $0.70 \%$ of all measurements and $3.52 \%$ of all patients respectively.

It is commonly accepted that this prevalence rate is mostly dependent on tooth-associated factors that increase the CEJ-ABC distance. Firstly, there is a strong association between the presence and extent of interproximal caries and marginal bone loss (Bimstein et al., 1994, Needleman et al., 1997, Bimstein et al., 1993b, Collares et al., 2018, Bimstein et al., 1996, Bimstein and Garcia-Godoy, 1994). Some authors found a similar association with the presence of fillings (Bimstein et al., 1994, Bimstein et al., 1996, Needleman et al., 1997). This was demonstrated in the current study as well. A radiographic study performed in adult subjects found a significant association between the presence of amalgam restorations and probing pocket depths $\geq 4 \mathrm{~mm}$. This correlation was not discovered with composite restorations. Since the current patient sample included rather recent radiographs, the presence of amalgam fillings is probably less common than in older similar studies, which may have attributed to the lower prevalence rate of alveolar bone loss. However, each restoration is associated with more clinical attachment loss and larger probing pocket depths, independently of the material (Collares et al., 2018).

Interestingly, some authors use a $2 \mathrm{~mm}$ CEJ-ABC distance while others choose a $3 \mathrm{~mm}$ cutoff value to correct for radiographic imprecisions. In the current study, a $2 \mathrm{~mm}$ cut-off point was used to define bone loss. Indeed, since this is a retrospective study there is no certainty on whether the standard radiographic procedure with filmholders was applied, which may attribute to a distortion in perpendicular projection. However, to our knowledge, this is the first study in this series that uses digital radiographs and excluded radiographs of low quality, which makes the measurements more precise. Therefore, we concluded that it was permitted to use a $2 \mathrm{~mm}$ distance as limit for a normal bone level. Nonetheless, a rather low inter- and intra-examiner agreement proves that these 
measurements are affected by a certain error, which raises the question whether the usage of a radiographic cut-off point alone is the best way to diagnose patients who are susceptible for further periodontal breakdown. However, one had to keep in mind that of the 32 measurements larger than $2 \mathrm{~mm}, 26$ (81\%) were assessed on a site diagnosed with one of the described risk factors. This means that only $19 \%$ of the enlarged measurements can be attributed to periodontitis. Radiographs are useful for screening but when the CEJ-ABC distance is $>2 \mathrm{~mm}$ clinical parameters such as bleeding, swelling and periodontal attachment level should be checked.

Unfortunately, since this study and previous trials are all cross-sectional, they give no information on the further development of the sites with bone loss. In general, there is a lack of longitudinal studies in this domain. To our knowledge there is only study of such kind, which performed a seven-year follow up of 9 children with pre-pubertal periodontitis after mechanical treatment combined with antiseptics and antibiotics (Bimstein, 2003). However, the study population was small and it did not investigate the progression of periodontitis before commencement of treatment. Long-term followup studies of the progression of bone loss in the absence of intervention might be of more value to assess the risk of further periodontal deterioration, but may entail some practical and ethical issues.

Previous studies clearly support a higher prevalence rate of alveolar bone loss in African, AfricanAmerican and Asian populations (Albandar, 2014, Sjödin and Matsson, 1994, Darby et al., 2005). However, some authors did not find this correlation, and others acknowledged a possible confounding factor due to a higher prevalence of caries and restorations in non-Caucasian children (Bimstein et al., 1994, Bimstein, 2018). Moreover, it has to be pointed out that older studies based their subdivision of the different ethnic groups mostly on the last name of the child. In today's evolving society, subdividing the children based on their last name is outdated and might not give an accurate representation of the correct ethnic background. Since this is a retrospective study and ethnic origin is not mentioned in the patient file, we chose not to investigate this.

In addition to dental parameters and ethnic background, other factors such as general health and medication might also influence the periodontal situation. However, the association with periodontitis is not supported unanimously in literature. Features of general health associated with periodontal disease are diabetes and certain syndromes such as Down syndrome and Papillon-Lefèvre (Lalla et al., 2007, Haritha and Jayakumar, 2011). Some genetic polymorphisms, for example in the interleukin-1 gene cluster, are also described to have a correlation with periodontitis but are not examined during a routine dental examination (Brett et al., 2005). Drug induced gingival overgrowth, for example caused by calcium channel blockers, might hinder a good 
oral hygiene and therefore increase the risk of early periodontal problems (Heasman and Hughes, 2014). Since this study focuses on dental parameters, this information was not collected.

As in other research domains, there is an enormous heterogeneity among the studies in this field, which makes comparison difficult. Different authors included completely different study populations and described correlations with different features of these subjects. The current study found a similar mean CEJ-ABC distance as described in earlier studies, but demonstrated a rather low prevalence rate of bone loss. Since this is the first study performing measurements on digital radiographs, the values might be more precise.

Even though these measurements have their shortcomings, bitewing radiographs remain a useful aid in clinical practice to screen for periodontal diseases since probing is a difficult act in children.

Correct assessment requires general dentists to have a basic knowledge about the factors that might influence the bone level. Moreover, awareness should be raised among dental professionals of the possibility of bone loss in the primary dentition and the associated risk of periodontal breakdown in the further dental development. 


\section{References}

Ainamo, J., Barmes, D., Beagrie, G., Cutress, T., Martin, J. \& Sardo-Infirri, J. (1982) Development of the World Health Organization (WHO) community periodontal index of treatment needs (CPITN). Int Dent J 32, 281-291.

Albandar, J. M. (2014) Aggressive and acute periodontal diseases. Periodontol 2000 65, 7-12. doi:10.1111/prd.12013.

Albandar, J. M., Baghdady, V. S. \& Ghose, L. J. (1991) Periodontal disease progression in teenagers with no preventive dental care provisions. J Clin Periodontol 18, 300-304. doi:10.1111/j.1600051X.1991.tb00432.x.

Bimstein, E. (1995) Radiographic diagnosis of the normal alveolar bone height in the primary dentition. J Clin Pediatr Dent 19, 269-271.

Bimstein, E. (2003) Seven-year follow-up of 10 children with periodontitis. Pediatr Dent 25, 389-396.

Bimstein, E. (2018) Radiographic Description of the Distribution of Aggressive Periodontitis in Primary Teeth. J Clin Pediatr Dent 42, 91-94. doi:10.17796/1053-4628-42.2.2.

Bimstein, E., E Delaney, J. \& A Sweeney, E. (1988) Radiographic assessment of the alveolar bone in children and adolescents. Pediatr Dent 10, 199-204.

Bimstein, E. \& Garcia-Godoy, F. (1994) The significance of age, proximal caries, gingival inflammation, probing depths and the loss of lamina dura in the diagnosis of alveolar bone loss in the primary molars. ASDC J Dent Child 61, 125-128.

Bimstein, E., Ranly, D. M., Skjonsby, S. \& Soskolne, W. A. (1993a) The effect of facial growth, attrition, and age on the distance from the cementoenamel junction to the alveolar bone crest in the deciduous dentition. Am J Orthod Dentofacial Orthop 103, 521-525.

Bimstein, E., Shapira, L., Landau, E. \& Sela, M. N. (1993b) The relationship between alveolar bone loss and proximal caries in children: prevalence and microbiology. ASDC J Dent Child 60, 99-103.

Bimstein, E. \& Soskolne, A. W. (1988) A radiographic study of interproximal alveolar bone crest between the primary molars in children. ASDC J Dent Child 55, 348-350.

Bimstein, E., Treasure, E. T., Williams, S. M. \& Dever, J. G. (1994) Alveolar bone loss in 5-year-old New Zealand children: its prevalence and relationship to caries prevalence, socio-economic status and ethnic origin. J Clin Periodontol 21, 447-450.

Bimstein, E., Zaidenberg, R. \& Soskolne, A. W. (1996) Alveolar bone loss and restorative dentistry in the primary molars. J Clin Pediatr Dent 21, 51-54.

Brett, P. M., Zygogianni, P., Griffiths, G. S., Tomaz, M., Parkar, M., D'Aiuto, F. \& Tonetti, M. (2005) Functional gene polymorphisms in aggressive and chronic periodontitis. J Dent Res 84, 11491153. doi:10.1177/154405910508401211.

Califano, J. V. (2003) Position paper: periodontal diseases of children and adolescents. J Periodontol 74, 1696-1704. doi:10.1902/jop.2003.74.11.1696.

Carranza, F., Garcia-Godoy, F. \& Bimstein, E. (1998) Prevalence of marginal alveolar bone loss in children. J Clin Pediatr Dent 23, 51-53.

Collares, K., Demarco, F. F., Horta, B. L. \& Correa, M. B. (2018) Proximal restoration increases the risk of clinical attachment loss. J Clin Periodontol 45, 832-840. doi:10.1111/jcpe.12919.

Darby, I. B., Lu, J. \& Calache, H. (2005) Radiographic study of the prevalence of periodontal bone loss in Australian school-aged children attending the Royal Dental Hospital of Melbourne. J Clin Periodontol 32, 959-965. doi:10.1111/j.1600-051X.2005.00767.x.

Garcia, R. I., Compton, R. \& Dietrich, T. (2016) Risk assessment and periodontal prevention in primary care. Periodontol 2000 71, 10-21. doi:10.1111/prd.12124. 
Haritha, A. \& Jayakumar, A. (2011) Syndromes as they relate to periodontal disease. Periodontol 2000 56, 65-86. doi:10.1111/j.1600-0757.2010.00363.x.

Heasman, P. A. \& Hughes, F. J. (2014) Drugs, medications and periodontal disease. Br Dent J 217, 411 419. doi:10.1038/sj.bdj.2014.905.

Jenkins, W. M. \& Papapanou, P. N. (2001) Epidemiology of periodontal disease in children and adolescents. Periodontol 2000 26, 16-32.

Lalla, E., Cheng, B., Lal, S., Kaplan, S., Softness, B., Greenberg, E., Goland, R. S. \& Lamster, I. B. (2007) Diabetes mellitus promotes periodontal destruction in children. J Clin Periodontol 34, 294298. doi:10.1111/j.1600-051X.2007.01054.x.

Marks, S. C., Jr. \& Schroeder, H. E. (1996) Tooth eruption: theories and facts. Anat Rec 245, 374-393. doi:10.1002/(sici)1097-0185(199606)245:2<374::Aid-ar18>3.0.Co;2-m.

Needleman, H. L., Ku, T. C., Nelson, L., Allred, E. \& Seow, W. K. (1997) Alveolar bone height of primary and first permanent molars in healthy seven- to nine-year-old children. ASDC J Dent Child 64, 188-196, 165.

Rasband, W. (1997) ImageJ. University of Wisconsin National Institutes of Health and the Laboratory for Optical and Computational Instrumentation.

Shapira, L., Tarazi, E., Rosen, L. \& Bimstein, E. (1995) The relationship between alveolar bone height and age in the primary dentition. A retrospective longitudinal radiographic study. $J$ Clin Periodontol 22, 408-412.

Sjödin, B. \& Matsson, L. (1992) Marginal bone level in the normal primary dentition. J Clin Periodontol 19, 672-678. doi:10.1111/j.1600-051X.1992.tb01717.x.

Sjödin, B. \& Matsson, L. (1994) Marginal bone loss in the primary dentition. J Clin Periodonto/ 21, 313-319. doi:10.1111/j.1600-051X.1994.tb00719.x.

Sjodin, B., Matsson, L., Unell, L. \& Egelberg, J. (1993) Marginal bone loss in the primary dentition of patients with juvenile periodontitis. J Clin Periodonto/ 20, 32-36. doi:10.1111/j.1600051X.1993.tb01756.x.

Sweeney, E. A., Alcoforado, G. A. P., Nyman, S. \& Slots, J. (1987) Prevalence and microbiology of localized prepubertal periodontitis. Oral Microbiology and Immunology 2, 65-70. doi:10.1111/j.1399-302X.1987.tb00292.x. 


\section{Tables}

Table 1. Demographic characteristics of investigated population

\begin{tabular}{ll}
\hline Number of radiographs & 1491 \\
Number of patients & 796 \\
$\mathrm{~N}^{\circ}$ boys & 418 \\
$\mathrm{~N}^{\circ}$ girls & 378 \\
Mean age (years) & $6.46 \pm 2.38$ \\
Age range (years) & $1-15$ \\
\hline
\end{tabular}

Table 2. Number $\left(\mathrm{n}^{\circ}\right)$ of measurements in each group, mean CEJ-ABC distance \pm SD and comparison of intergroup differences

\section{$n^{\circ}$ measurements Mean \pm SD $\quad$ p-value}

\begin{tabular}{|c|c|c|c|}
\hline All deciduous teeth & 4585 & $0.93 \pm 0.37$ & \\
\hline Upper jaw & 2145 & $0.98 \pm 0.37$ & \multirow{2}{*}{$<0.001$} \\
\hline Lower jaw & 2440 & $0.89 \pm 0.38$ & \\
\hline Boys & 2423 & $0.95 \pm 0.40$ & \multirow{2}{*}{0.05} \\
\hline Girls & 2162 & $0.91 \pm 0.34$ & \\
\hline $\begin{array}{l}\text { Mesial second deciduous molar } \\
\text { upper jaw }\end{array}$ & 1124 & $0.96 \pm 0.36$ & \multirow{4}{*}{$<0.05$} \\
\hline $\begin{array}{l}\text { Distal first deciduous molar } \\
\text { upper jaw }\end{array}$ & 1021 & $1.01 \pm 0.37$ & \\
\hline $\begin{array}{l}\text { Mesial second deciduous molar } \\
\text { lower jaw }\end{array}$ & 1332 & $0.83 \pm 0.41$ & \\
\hline $\begin{array}{l}\text { Distal first deciduous molar } \\
\text { lower jaw }\end{array}$ & 1108 & $0.96 \pm 0.32$ & \\
\hline $\begin{array}{l}\text { Risk factor on tooth surface or } \\
\text { adjacent tooth surface }\end{array}$ & 2695 & $0.96 \pm 0.40$ & \multirow[t]{2}{*}{$<0.001$} \\
\hline Healthy surface & 1890 & $0.90 \pm 0.34$ & \\
\hline Risk factor on surface itself & 787 & $0.99 \pm 0.37$ & \multirow{2}{*}{$<0.001$} \\
\hline Healthy surface & 1890 & $0.90 \pm 0.34$ & \\
\hline Risk factor on adjacent surface & 549 & $0.88 \pm 0.37$ & \multirow{2}{*}{0.355} \\
\hline Healthy surface & 1890 & $0.90 \pm 0.34$ & \\
\hline $\begin{array}{l}\text { Caries on tooth surface or } \\
\text { adjacent tooth surface }\end{array}$ & 1888 & $0.96 \pm 0.41$ & 0.004 \\
\hline
\end{tabular}




\begin{tabular}{|c|c|c|c|}
\hline No caries & 2697 & $0.91 \pm 0.35$ & \\
\hline $\begin{array}{l}\text { Filling on tooth surface or } \\
\text { adjacent tooth surface }\end{array}$ & 860 & $0.96 \pm 0.36$ & \multirow[t]{2}{*}{0.012} \\
\hline No filling & 3725 & $0.93 \pm 0.38$ & \\
\hline $\begin{array}{l}\text { Calculus on tooth surface or } \\
\text { adjacent tooth surface }\end{array}$ & 2 & $1.25 \pm 0.21$ & \multirow{2}{*}{$\begin{array}{l}\text { p-value not determinec } \\
\text { due to insufficient } \\
\text { measurements with } \\
\text { calculus }\end{array}$} \\
\hline No calculus & 4583 & $0.93 \pm 0.37$ & \\
\hline $\begin{array}{l}\text { Pulp pathology on tooth surface } \\
\text { or adjacent tooth surface }\end{array}$ & 654 & $0.97 \pm 0.50$ & \multirow[t]{2}{*}{$<0.001$} \\
\hline No pulp pathology & 3931 & $0.93 \pm 0.35$ & \\
\hline $\begin{array}{l}\text { Steel crown on tooth surface or } \\
\text { adjacent tooth surface }\end{array}$ & 38 & $0.94 \pm 0.36$ & \multirow[t]{2}{*}{0.120} \\
\hline No steel crown & 4547 & $0.93 \pm 0.38$ & \\
\hline $\begin{array}{l}\text { Erupting/exfoliating } \\
\text { neighboring tooth }\end{array}$ & 170 & $1.07 \pm 0.44$ & \multirow[b]{2}{*}{0.142} \\
\hline $\begin{array}{l}\text { No erupting/exfoliating } \\
\text { neighboring tooth }\end{array}$ & 4415 & $0.93 \pm 0.37$ & \\
\hline
\end{tabular}

Bold: significant intergroup differences

Table 3. Distribution of CEJ-ABC measurements $>2 \mathrm{~mm}$

\begin{tabular}{lll}
\hline & $\mathbf{n}^{\circ}$ patients/measurements & \% of total population \\
\hline Patients & 28 & 3.52 \\
Boys & 23 & 0.06 \\
Girls & 5 & 0.01 \\
\hline Measurements & 32 & 0.70 \\
\hline
\end{tabular}

Table 4. Correlation between measurements $>2 \mathrm{~mm}$ (\% of measurements with presence/absence of pathology that were higher than $2 \mathrm{~mm}$ )

\begin{tabular}{lll}
\hline & $\begin{array}{l}\mathbf{n}^{\circ} \text { measurements } \\
>\mathbf{2} \mathbf{~} \mathbf{m}(\%)\end{array}$ & p-value \\
\hline Mesial second deciduous molar upper jaw & $3(9)$ & $>0.05$ \\
Distal first deciduous molar upper jaw & $7(22)$ & \\
Mesial second deciduous molar lower jaw & $12(38)$
\end{tabular}




\begin{tabular}{|c|c|c|}
\hline Distal first deciduous molar lower jaw & \multicolumn{2}{|l|}{$10(31)$} \\
\hline Second deciduous molar & $15(47)$ & \\
\hline & & $>0.05$ \\
\hline First deciduous molar & $17(53)$ & \\
\hline Upper jaw & $10(31)$ & \\
\hline & & $<0.001$ \\
\hline Lower jaw & $22(69)$ & \\
\hline Boys & $27(84)$ & \\
\hline & & 0.054 \\
\hline Girls & $5(16)$ & \\
\hline $\begin{array}{l}\text { Risk factor on tooth surface or adjacent tooth } \\
\text { surface }\end{array}$ & $26(81)$ & $<0.001$ \\
\hline No risk factor & $6(19)$ & \\
\hline $\begin{array}{l}\text { Caries on tooth surface or adjacent tooth } \\
\text { surface }\end{array}$ & $16(50)$ & 0.11 \\
\hline No caries & $16(50)$ & \\
\hline Caries on tooth surface & $3(16)$ & \\
\hline & & $<0.001$ \\
\hline No caries & $16(84)$ & \\
\hline $\begin{array}{l}\text { Filling on tooth surface or adjacent tooth } \\
\text { surface }\end{array}$ & $8(25)$ & 0.99 \\
\hline No filling & $24(75)$ & \\
\hline Filling on tooth surface & $3(11)$ & \\
\hline & & $<0.001$ \\
\hline No filling & $24(89)$ & \\
\hline $\begin{array}{l}\text { Calculus on tooth surface or adjacent tooth } \\
\text { surface }\end{array}$ & $0(0)$ & $\begin{array}{l}\mathrm{p} \text {-value not determined due } \\
\text { to insufficient }\end{array}$ \\
\hline No calculus & $32(100)$ & measurements with calculus \\
\hline $\begin{array}{l}\text { Pulp pathology on tooth surface or adjacent } \\
\text { tooth surface }\end{array}$ & $10(31)$ & $<0.001$ \\
\hline No pulp pathology & $22(69)$ & \\
\hline
\end{tabular}




\begin{tabular}{lll}
\hline $\begin{array}{l}\text { Steel crown on tooth surface or adjacent } \\
\text { tooth surface }\end{array}$ & $1(3)$ & $\begin{array}{l}\text { p-value not determined due } \\
\text { to insufficient } \\
\text { measurements with steel } \\
\text { crown }\end{array}$ \\
\hline No steel crown & $31(97)$ & 0.820 \\
\hline Erupting/exfoliating neighboring tooth & $5(16)$ & \\
No erupting/exfoliating neighboring tooth & $27(84)$ &
\end{tabular}

Bold: significant intergroup differences 
Figure legends

Figure 1. A straight line is drawn for measuring the CEJ-ABC distance $(\mathrm{mm})$.

Figure 2. CEJ-ABC distance ( $\mathrm{mm}$ ) in relation to the age (years).

Figure 3. Boxplot comparing the CEJ-ABC distance $(\mathrm{mm})$ on sites with a risk factor on the tooth surface or adjacent surface to healthy sites

\section{Explanation:}

CEJ = cemento-enamel junction

$\mathrm{ABC}=$ alveolar bone crest

Healthy sites $=$ no risk factor was diagnosed on the surface itself or the adjacent surface 